* Doutoranda em Ciências da Linguagem pela Universidade do Vale do Sapucaí- UNIVÁS; Mestre em Administração Pública pela Universidade Federal de Lavras UFLA e graduada em Direito pela Universidade de Itaúna.E-mail: erikaloureiro.borba@gmail.com

**Doutor em Administração de Organizações pela Universidade de São Paulo (2014) e Professor do Programa de Pós-Graduação em Administração Pública da Universidade Federal de Lavras (UFLA).E-mail: denis.oliveira@, ufla.br

\section{OS CONSÓRCIOS INTERMUNICIPAIS: ENTRE BARREIRAS E Potencialidades}

\author{
The InTERMunicipal PARTNershiPs: BetweEN BARRIERS \\ AND Potentialities
}

CONSTRUCCIONES INTERMUNICIPALES: ENTRE BARRERAS Y PotenCIALIDADES

\section{Érika Loureiro Borba* Dênis Renato de Oliveira**}

Como citar: BORBA, Érika Loureiro; OLIVEIRA, Dênis Renato de. Os consórcios intermunicipais: entre barreiras e potencialidades. Revista do Direito Público, Londrina, v. 15, n. 2, p. 135-154, ago. 2020. DOI: 10.5433/24157-108104-1.2020v1 5n2p.135. ISSN: 1980-511X

Resumo: A cooperação entre os entes federados se mostra essencial para que interesses comuns sejam contemplados com maior eficiência, especialmente quando se trata da esfera municipal. O presente estudo tem por objetivo apontar as principais barreiras e potencialidades encontradas pelos municípios para implementação dos consórcios intermunicipais a partir de estudos de caso publicados entre 2014 e 2018. Para tanto utilizou-se como arcabouço metodológico a pesquisa bibliométrica e a análise de conteúdo. Conclui-se que a utilização dos consórcios públicos, dentro do contexto da administração pública brasileira, se mostra como uma alternativa capaz de contribuir para promoção do desenvolvimento local e melhoria da prestação dos serviços públicos.

Palavras-chave: Consórcios intermunicipais. Gestão pública. Redes de cooperação.

Abstract: Cooperation between federal entities is essential for upholding common interests, especially in the case of municipal interests. This study investigates municipal barriers in the context of intermunicipal partnerships from an analysis of various case studies published between 2014 and 2018. For this purpose, this paper utilizes bibliographic research as its method. In conclusion, the use of public partnerships, within the context of the Brazilian public sector, can contribute to the promotion of local development and improve public services. 
Keywords: Intermunicipal partnerships; Public administration; Cooperation networks.

Resumen: La cooperación entre los entes federados se muestra esencial para que intereses comunes sean contemplados con mayor eficiencia, especialmente cuando se trata de la esfera municipal. El presente estudio tiene por objetivo apuntar las principales barreras y potencialidades encontradas por los municipios para implementación de los consorcios intermunicipales a partir de estudios de caso publicados entre 2014 y 2018. Para ello se utilizó como marco metodológico la investigación bibliométrica y el análisis de contenido. Concluyendo que la utilización de los consorcios públicos, dentro del contexto de la administración pública brasileña, se muestra como una alternativa capaz de contribuir a la promoción del desarrollo local y la mejora de la prestación de los servicios públicos.

Palabras clave: Consorcios intermunicipales. Gestión pública. Redes de cooperación. 


\section{INTRODUÇÃO}

A administração pública busca a utilização racional dos recursos do Estado para atingir fins determinados que visem à promoção do interesse público. Considerando que o cenário onde as atividades estatais se desenvolvem é dinâmico em decorrência da interação entre os atores sociais e o Estado, e a democratização do espaço público foi facilitada pela globalização e pela evolução tecnológica, que reduziu as distâncias entre a sociedade e a efetivação das políticas devido à ampliação dos meios de participação (SARAVIA, 2006), para que o Estado pudesse exercer de forma mais eficiente suas funções, foi necessária a repartição de poderes e deveres entre os entes federados.

O federalismo implica na divisão espacial dos Poderes e uma multiplicidade de organizações governamentais com atribuições e competências próprias. No caso brasileiro há a divisão entre União, estados, Distrito Federal e municípios, pessoas jurídicas de direito público cujas prerrogativas de cada ente estão previstas na Constituição Federal de 1988.

Após promulgação desse marco jurídico, os municípios brasileiros passaram a ter maiores encargos, principalmente no que diz respeito à prestação de serviços que contemplem os direitos sociais. Porém, é preciso destacar o desequilíbrio que ocorre a partir da implementação do pacto federativo, tendo em vista que os municípios passaram a ter mais deveres para com a população, mas os recursos nem sempre são suficientes para o atendimento das demandas (REZENDE, 2011).

Uma forma de tentar superar tal desequilíbrio é a atuação dos municípios em regime de cooperação via consórcio público, por exemplo. Estes consórcios surgiram devido a constatação de que os municípios, por si só, não teriam condições de promover as políticas públicas demandadas pela população (ABRUCIO; FILIPPIM; DIEGUEZ, 2013). A lei orientadora dos consórcios é a 11.107/07, regulamentada pelo Decreto 6017/07, buscando institucionalizar esta forma de cooperação.

Sendo assim, busca-se responder a seguinte questão: quais são as barreiras e potencialidades para implementação dos consórcios intermunicipais a partir de estudos de caso publicados entre os anos de 2014 a $2018 ?$

O tema se justifica devido a sua relevância no cenário de gestão municipal, por ser uma prática que tem potencial para ajudar na promoção do desenvolvimento local e pela forte tendência descentralizadora que vem se desenhando no âmbito da Administração Pública brasileira. Segundo Cohn (2002), os municípios encontram-se obrigados a implementar cada vez mais grupos de serviços públicos que deixaram de ser ofertados pelos outros entes federados, por isso, cria-se uma gama de desafios complexos que exigem gestões mais eficientes. E uma das alternativas para este novo rearranjo são os consórcios intermunicipais. 
De acordo com dados apresentados pelo IPEA(LINHARES; MESSENBERG;FERREIRA, 2017), mais de 3100 municípios estão participando de algum consórcio intermunicipal, porém, no ano de 2012 eram apenas 401. Tendo em vista este crescimento expressivo, torna-se fundamental a compreensão acerca dos fatores, limites e possibilidades que impactam na implementação destes consórcios.

Desta forma, o objetivo geral deste estudo é apontar as principais barreiras e potencialidades encontradas pelos municípios para implementação dos consórcios intermunicipais a partir de estudos de caso publicados entre 2014 e 2018.

Os consórcios intermunicipais representam uma forma inovadora para a resolução de problemas a partir da exploração das potencialidades locais e articulação direta e indireta dos agentes. Para Matos e Dias (2011, p. 503), estes consórcios viabilizam que municípios reúnam esforços para buscarem a resolução de problemas comuns, podendo ser criados a partir de simples pacto entre prefeitos ou possuírem personalidade jurídica própria.

Porém, estudos como o de Calderan, Mazzarino, Turati (2017) apontam o desconhecimento de alguns gestores públicos sobre como implementar tais consórcios. Por isso, fortalecer a lógica de consorciamento intermunicipal se faz relevante para que os municípios tenham maiores condições de implementarem políticas públicas mais robustas e eficientes no que diz respeito à promoção do interesse público.

A metodologia utilizada para a análise dos dados foi a pesquisa bibliométrica e a análise de conteúdo. Esse estudo está divido em capítulos que tratam das temáticas: o federalismo e descentralização administrativa; redes de cooperação intermunicipal e consórcios públicos no Brasil.

\section{A DESCENTRALIZAÇÃO ADMINISTRATIVA E OS MUNICÍPIOS NO CONTEXTO DO FEDERALISMO BRASILEIRO}

A principal atividade do Estado é promover o bem-estar social, o que ressalta sua função intervencionista na vida social, política e econômica da sociedade. Esta intervenção é indispensável quando se trata de federalismo, regulando, administrando a sociedade (LIMA, 2008). O Estado foi criado porque a sociedade cedeu parte de seus direitos individuais em prol de um bem maior, que se revela na defesa dos interesses públicos. Se cada indivíduo buscasse apenas o que é de seu interesse próprio, toda a sociedade viveria em guerras e conflitos, e o bem comum nunca seria alcançado. O objetivo do Estado é zelar e de defender os interesses sociais, bem como evitar o caos (BORBA; PEREIRA; TORRES, 2012).

A nova ordem estatal, cuja característica é a descentralização, surgiu a partir da comprovação do desgaste do poder dos Estados nacionais. O federalismo faz parte do rearranjo estatal e possui como principal característica o redirecionamento dos governos para provisão dos 
serviços sociais (VIANA; LIMA; OLIVEIRA, 2002). E implica na repartição do poder político que o Estado tem, em seus vários níveis de governo, ou seja, União, Estados-Membros, Distrito Federal e Municípios. Para tanto, a Constituição Federal, que garantiu a cada um desses entes autonomia política, administrativa e financeira, como também competências suficientes para criar normas e executar suas responsabilidades (OLIVEIRA, 2013).

O sistema federalista permite a união de estados e municípios com maior autonomia interna, e também um ente público para tratar de assuntos internacionais, por isso, segundo Lima (2008) este sistema vem se tornando uma orientação que pode contribuir para impulsionar a união e fortalecimento de uma nação. A Constituição Federal de 1988, ao elevar o município ao mesmo patamar onde se encontram a União e os Estados, dotou-o de uma gama de competências onde por meio delas tornou-se possível o exercício de suas atividades. A regra básica determinante da seara de competência constitucional do município reside exatamente naquilo tudo que se encaixa dentro do chamado interesse local.

Desta forma, o município, que é reconhecido como ente federado e que, segundo Meirelles (2008, p. 47) que "sempre fez parte da Federação. E a Constituição de 1988 assim o declarou em seus arts. $1^{\circ}$ e 18, corrigindo essa falha". Para tanto, a Carta Magna ao longo de seu texto prevê poderes autônomos aos municípios para agir em interesses locais, descentralizando o poder do estado, que é característico do federalismo. No Brasil, portanto, tem-se a União, que é o poder central, os Estados e Distrito Federal que estão em seu nível intermediário, e os municípios no domínio de suas ações locais. Os membros federados têm autonomia para administrar, legislar e executar seus projetos políticos e econômicos, observando-se, por óbvio, os comandos da Lei Maior.

Os Municípios brasileiros apresentam inúmeras peculiaridades que lhes dão forma dentro do plano da Federação nacional que fazem com que os mesmos se destaquem em relação aos demais municípios de todas as outras Federações do mundo.

Durante um longo período a administração pública esteve circunscrita aos padrões centralizadores que, até então, eram reconhecidos como composição de um modelo eficiente. Devido à crise do modelo burocrático e as discussões sobre a reforma do Estado, este modelo estatal centralizador passou a ser visto como obsoleto e ineficiente (MONTEIRO, 2011).

As reformas da Administração Pública, promovidas nas décadas de 80 e 90, fomentaram a descentralização administrativa como forma de retomada da eficiência das ações públicas.

É preciso ressaltar que a descentralização administrativa impulsiona a desconcentração territorial e funcional por meio da delegação de funções e aumento do poder decisório (dimensão política) das camadas hierárquicas mais baixas. A descentralização também implica no fortalecimento do pacto federativo que, no caso brasileiro, promoveu a ampliação da competência decisória dos municípios (BENTO, 2003).

A descentralização é um processo que possibilita o Estado realizar suas funções através de 
pessoas jurídicas titulares de competências constitucionais específicas e delimitadas, ou seja, estas atribuições decorrem do poder central e tem como objetivo a consecução dos serviços públicos (CABRAL NETO, 2010), e só foi possível devido ao embasamento da administração gerencial, que tem por princípio norteador justamente a transferência do poder decisório para as instâncias mais baixas da Administração Pública (MONTEIRO, 2011).

Desta forma, é possível dizer que a descentralização "define a competência das três esferas governamentais proporcionando os elementos necessários ao desenvolvimento de ações sociais descentralizadas, complementares e não paralelas" (FREITAS, 2015, p. 2). Para Abrúcio (2006), a descentralização é vista como um processo político que envolve a transferência do poder decisório aos entes federados, permitindo que os mesmos tenham liberdade para operacionalizar sua gestão, incluindo as estruturas financeiras e tributárias. E Bresser-Pereira (2009) acrescenta que este processo envolve a transferência de responsabilidades para o melhor atendimento das demandas locais que, por outro lado, acaba por favorecer também o controle sociais destas ações.

Cabe ressaltar que são considerados efeitos positivos da descentralização: maior flexibilidade e agilidade na prestação dos serviços públicos; melhor adaptação e aproximação com os cidadãos; melhor capacidade de inovação, produtividade e criatividade. E como dificuldades deste processo tem-se: dificuldade de renúncia de parte do poder da alta administração, investimento na capacitação técnica dos agentes envolvidos, independência financeira dos municípios, quando o processo de descentralização ocorre sem a implementação de políticas redistributivas, pode resultar no agravamento das desigualdades entre as regiões (ABRUCIO, 2006; BENTO, 2003; MONTEIRO, 2011).

\section{REDES DE COOPERAÇÃO INTERMUNICIPAL}

O tema cooperação se tornou fundamental na agenda política e de pesquisa, advindo das discussões acerca da centralização e descentralização que, por si só, já não basta para a compreensão da dinâmica do federalismo brasileiro (ABRUCIO; FILIPPIM; DIEGUEZ, 2013). A cooperação surge pela existência de interesses comuns entre os entes federados e a discussão ganhou força devido ao resultado das fragilidades e desafios decorrentes do processo de descentralização, principalmente devido às transferências do poder de decisão e recursos e as novas atribuições dos entes estaduais e municipais (ROCHA; FARIA, 2004).

É uma estratégia que exige capacitação e aprendizado dos seus integrantes. Envolve ações de cooperação, colaboração, intraempreendedorismo, inovação e a preservação da autonomia dos participantes muito embora permita a subordinação hierárquica entre os participantes (CORREIA FILHO; BAGGIO; MELO, 2017). Já no que diz respeito à sua formação, as redes podem ser vistas "como uma alternativa também para o setor público, pois os elaboradores de políticas na contemporânea sociedade interligada estão constantemente se confrontando com problemas cada vez mais complexos que requerem cada vez mais a ação coletiva." (FREITAS JÚNIOR; 
MESQUITA, 2010, p. 3).

Diz-se necessário, portanto, conduzir estudos que tragam luz para a discussão sobre os mecanismos de coordenação e parceria envolvendo os níveis de governo, cujo resultado seja a propositura de ações para a resolução de problemas comuns e problemas no campo das políticas públicas (ABRUCIO; FILIPPIM; DIEGUEZ, 2013).

Os consórcios ou redes de cooperação intermunicipais são uma forma de articulação do capital social cujas relações de auxílio mútuo, além de contribuírem para a resolução de problemas, também reforçam o poder dessas relações no âmbito social, favorecendo ganhos conjuntos (ABRUCIO; FILIPPIM; DIEGUEZ, 2013). Os consórcios intermunicipais "são uma forma de associação ou união de municípios calcada na percepção de um compartilhamento de interesses e propósitos (ROCHA; FARIA, 2004, p.86). Trata-se de uma inovação que aplica novos métodos organizacionais na prática do negócio, organização do trabalho ou mesmo nas relações externa à organização (CORREIA FILHO; BAGGIO; MELO, 2017).

De acordo com Abrúcio, Sano e Sydow (2011), a partir da constatação de que nenhum município consegue implementar todas as políticas públicas e que se tem buscado soluções cooperadas, é que surgem os consórcios. A cooperação neste caso contribui não somente para a otimização das políticas públicas, integração, difusão de informações e experiencias, como também para uma distribuição mais igualitária de custos e benefícios entre os entes participantes (ROCHA; FARIA, 2004).

Na perspectiva de Borges (2006) os consórcios contribuem para que os municípios e estados mais carentes de recursos tenham condições de compartilhar tais recursos, buscando maior eficiência na prestação dos serviços públicos, o aumento da capacidade desses entes na resolução de problemas comuns, maior atratividade no que tange a captação de investimentos privados e demais formas de financiamento.

A previsão de criação de consórcios intermunicipais consta na legislação brasileira desde a Constituição Federal de 1937, os quais ficavam subordinados em grande monta à política estadual. Foi a partir da redemocratização que este instrumento se fortaleceu e passou a contar com a já apresentada Lei 11.107/05 (ABRUCIO; FILIPPIM; DIEGUEZ, 2013).

As redes de consórcios intermunicipais têm início por meio de acordo firmado entre os gestores municipais cujo resultado é a produção de um documento oficial contendo todos os compromissos firmados, para depois proceder com a criação de uma pessoa jurídica que será responsável pela administração dos interesses coletivos, que deve ser materializada obrigatoriamente por meio de uma sociedade civil sem fins lucrativos (CORREIA FILHO; BAGGIO; MELO, 2017). Envolvem, necessariamente, pessoas jurídicas de direito público, de mesma natureza jurídica ou mesmo nível de governo.

Os consórcios se diferem dos convênios porque neste último é possível a associação entre pessoas físicas ou jurídicas de direito público ou privado. Ressalta- se que é possível que 
os consórcios intermunicipais estabeleçam parcerias com diversas instituições e atores sociais como, por exemplo, organizações não-governamentais, universidades, secretarias municipais e secretarias estaduais (ROCHA; FARIA, 2004).

Os consórcios podem ser constituídos para atender diversas áreas como tratamento de lixo; proteção ambiental; implantação de serviços públicos; fomento da educação; e realização de obras públicas. No Brasil o consórcio que mais se destaca é o de saúde, por ser o mais utilizado (ROCHA; FARIA, 2004). Na perspectiva de Correia Filho, Baggio e Melo (2017) os principais benefícios das redes de consórcios intermunicipais são o incremento dos serviços públicos, aumento da eficiência, redução dos custos operacionais, ganhos de escala, mais flexibilização na celebração do contrato, etc.

Existem alguns fatores, evidenciados por Rocha e Faria (2004), que causam impacto na operacionalização das redes de cooperação intermunicipais, são eles: regras que incentivem a cooperação horizontal e vertical, pela criação de mecanismos formais como, por exemplo, leis e normas; reforço da capacidade de coordenação das esferas estadual e federal para facilitar a implementação; a burocracia, materializada pela existência de regras de seleção, motivação e critérios de promoção; tradição ou não de interação e comunicação entre os municípios; simetria entre os parceiros, que resulta no fortalecimento dos entes mais frágeis; existência ou não de mecanismos de participação da sociedade; aumento do poder de pressão e negociação dos municípios em face dos entes federais e estaduais.

As redes de cooperação intermunicipais, de acordo com Rocha e Faria (2004), podem resultar em efeitos negativos como subordinação dos entes mais fracos aos mais fortes, falta de clareza sobre a distribuição das responsabilidades, o que dificulta inclusive a fiscalização; e a falta de estímulo para a inovação nas formas de atuação dos entes participantes.

\section{OS CONSÓRCIOS PÚBLICOS NO BRASIL}

A criação da pessoa jurídica denominada consórcio público tomou forma a partir da promulgação da Lei 11.107 de 2005. Sua configuração decorre de uma reunião de pessoas jurídicas de diretos privado e/ou direito público, como parte integrante de administração pública indireta (RIBEIRO; RAZUK, 2014).

O objetivo da lei é a consolidação da gestão associada entre os entes federados para a promoção do interesse comum de resolução de atividades complexas (RODRIGUES, 2013/2014). Sua criação deriva de preceito constitucional presente no artigo 241, que diz:

Art. 241. A União, os Estados, o Distrito Federal e os Municípios disciplinarão por meio de lei os consórcios públicos e os convênios de cooperação entre os entes federados, autorizando a gestão associada de serviços públicos, bem como a transferência total ou parcial de encargos, serviços, pessoal e bens essenciais à 
continuidade dos serviços transferidos (BRASIL, 1988).

É preciso dizer que é possível ter um consórcio público com outra finalidade para além da gestão associada dos serviços públicos (ALEXANDRINO; PAULO, 2017). Os consórcios podem firmar convênios e participarem da contratação da administração direta e indireta sem a necessidade de licitação (CORREIA FILHO, BAGGIO, MELO, 2017).

O consórcio público não é um contrato administrativo tendo em vista que as vontades dos parceiros são convergentes (RIBEIRO, RAZUK, 2014). Nos contratos o Poder Público, em defesa do interesse público, celebra uma avença com a outra parte cujo intuito é a obtenção de lucro. Já nos consórcios, a gestão é associada e, por isso, todos os participantes visam o bem comum cuja finalidade é atender justamente a sociedade (CARVALHO, 2017).

Destaca-se que o consórcio no modelo horizontal envolve a atuação de entes que pertencem à mesma esfera governamental. Já o consórcio no modelo vertical é aquele em que atuam parceiros de esferas governamentais diferentes (CORREIA FILHO; BAGGIO; MELO, 2017). Porém, a União só pode participar quando todos os estados também estão participando.

De acordo com a Lei 11.107 de 2005, as etapas para constituição de consórcio são: a) elaboração do protocolo de intensões, especificando o nome, denominação, objeto, prazo de duração, sede, quais são os entes consorciados, a abrangência e forma de atuação, competência, os direitos e deveres dos participantes, e a estrutura organizacional; b) ratificação do protocolo de intensões por meio de lei aprovada pelo Legislativo de cada ente consorciado; c) elaboração do estatuto que deverá conter as formas de organização e estrutura administrativa, os cargos e funções, competências e atribuições, regras de operacionalização e formas de eleição para os cargos criados; este estatuto deve ser aprovado pela Assembleia Geral e publicado na imprensa oficial; d) personificação do consórcio; e) contrato de rateio; f) contrato de programa (OLIVEIRA, 2017).

No artigo $4^{\circ}$, incisos XI e XII da Lei 11.107 de 2005, estão as cláusulas que devem estar presentes no protocolo de intensões:

- a autorização para a gestão associada de serviços públicos, explicitando: as competências cujo exercício se transferiu ao consórcio público;

os serviços públicos objeto da gestão associada e a área em que serão prestados; a autorização para licitar ou outorgar concessão, permissão ou autorização da prestação dos serviços;

as condições a que deve obedecer o contrato de programa, no caso de a gestão associada envolver também a prestação de serviços por órgão ou entidade de um dos entes da Federação consorciados;

os critérios técnicos para cálculo do valor das tarifas e de outros preços públicos, bem como para seu reajuste ou revisão; e

- o direito de qualquer dos contratantes, quando adimplente com suas obrigações, de exigir o pleno cumprimento das cláusulas do contrato de consórcio público (BRASIL, 2005). 
Para a formação da Assembleia Geral devem ser estabelecidos os cargos de Presidência e Diretoria Executiva, cujos responsáveis são do Diretor Geral e o Diretor Administrativo e Financeiro, e a equipe técnica e administrativa. Os recursos para a operacionalização dos consórcios podem vir de repasse da União, estados ou municípios, convênios, contratos ou parcerias, prestação de serviços técnicos, repasses de entidades públicas e privadas, doações, operações de crédito e aplicações financeiras (CORREIA FILHO; BAGGIO; MELO, 2017).

Os entes participantes somente farão o repasse de recursos ao consórcio mediante a apresentação de contrato de rateio, que deve ser formalizado em cada novo exercício financeiro, de forma que o prazo de vigência não seja superior ao das dotações que o sustentam, com exceção dos contratos referentes a programas já previstos no plano plurianual ou a gestão associada de serviços públicos que são custeados por tarifas e preços públicos. O ente que não realizar a suficiente consignação da dotação será excluído do consórcio (MEDAUAR, 2018).

Os consórcios públicos representam uma inovação que pode resultar em avanços no campo da gestão pública, especialmente no que diz respeito às políticas públicas e sociais que implicam no trabalho conjunto de diversos entes para a delimitação de suas metas e objetivos e posterior implementação.

Segundo Di Pietro (2018), os privilégios concedidos pela Lei 11.107/05 aos consórcios tanto de natureza pública quanto de natureza privada são: a) a possibilidade de promover desapropriação e servidão a partir da declaração de utilidade ou necessidade pública; b) a possibilidade de compor contrato com a Administração direta e indireta sem a necessidade de licitação; c) o estabelecimento de limites mais elevados no que diz respeito à escolha da modalidade de licitação; d) dispensa de licitação na celebração de contrato de prestação de serviços públicos de forma associada dentro dos limites autorizados no contrato de consórcio ou convênio de cooperação; e) estipulação de valores mais elevados nos casos de dispensa de licitações em razão do valor.

Os consórcios estão sujeitos a fiscalização contábil, operacional e patrimonial de responsabilidade do tribunal de contas competente para analisar as contas do Chefe do Poder Executivo representante legal do consórcio. O limite territorial para sua atuação, segundo Farias (2017), corresponde à jurisdição de seus integrantes.

A alteração ou extinção do consórcio deverá ser feita por meio de instrumento aprovado pela Assembleia Geral e ratificado mediante lei por todos os participantes. Destaca-se que até que se tenha decisão sobre a responsabilidade por cada obrigação, os entes responderão de forma solidária pelas mesmas, cabendo ação de regresso em face dos entes beneficiados ou daqueles que deram causa ao surgimento da obrigação. E a retirada de um ente da federação do consórcio público só acontece por meio de ato forma do representante da Assembleia Geral, de acordo com a lei criadora do consórcio. Por fim, segundo Di Pietro (2018), os bens repassados ao consórcio, pelo participante que se retira, somente poderá ser revertido se houver previsão expressa no contrato do 
consórcio ou em instrumento de transferência ou alienação.

\section{PROCEDIMETNOS METODOLÓGICOS}

Este estudo tem como foco principal compreender as barreiras e potencialidades que se apresentam no processo de implementação dos consórcios intermunicipais a partir de estudos de caso publicados em periódicos entre os anos de 2014 e 2018. Para tal investigação optouse pelo embasamento metodológico advindo da pesquisa qualitativa, que se pauta pelo estudo da realidade pela análise de dados subjetivos, opiniões e fenômenos, usando a perspectiva do paradigma interpretativista.

Desta forma, Minayo (1995, p. 21-22) considera que:

[...] a pesquisa qualitativa responde a questões muito particulares. Ela se preocupa, nas ciências sociais, com um nível de realidade que não pode ser quantificado, ou seja, ela trabalha com o universo de significados, motivos, aspirações, crenças, valores e atitudes, o que corresponde a um espaço mais profundo das relações dos processos e dos fenômenos que não podem ser reduzidos à operacionalização de variáveis.

A pesquisa qualitativa tem como características o ambiente natural como fonte direta de dados que são, em sua maioria, descritivos, e a postura do pesquisador como instrumento-chave na tradução dos significados que os indivíduos dão às situações abordadas (BOGDAN; BIKLEN apud TRIVIÑOS, 1992).

Já o paradigma interpretativista se pauta pela compreensão da estrutura social como resultado da interpretação que os indivíduos realizam para pautar seu modo de agir. A sociedade é compreendida como uma criação de seus membros com foco na influência da interpretação do comportamento. Os teóricos ressaltam a necessidade de concentrar o estudo em nível micro de análise social, assim, a sociedade deve ser pensada como resultado final da interação humana, não sua causa. Desta forma, o pesquisador só entenderá a formação da ordem social através da observação da interação dos seres humanos (ALENCAR, 2000).

Esta pesquisa possui caráter exploratório e esta finalidade será alcançada por meio da realização de pesquisa bibliométrica, utilizada para a seleção de artigos que tratem da implementação dos consórcios públicos, a partir de estudos já realizados. Segundo Araújo e Alvarenga (2011, p. 51) "a bibliometria, como área de estudo da ciência da informação, tem um papel relevante na análise da produção científica de um país, uma vez que seus indicadores retratam o grau de desenvolvimento de uma área do conhecimento de um campo científico ou de saber.”

E, de acordo com Hayashi (2013), a análise bibliométrica pode ser aplicada para o mapeamento da leitura referente a uma área específica; para a produção de modelagem matemática 
identificando áreas de excelência, temas emergentes e lacunas, redes de colaboração; e para a produção de indicadores bibliométricos.

A bibliometria auxilia na construção de parâmetros que viabilizem a compilação quantitativa dos dados para a criação de uma leitura de referência (HAYASHI, 2013). Desta forma, o levantamento dos dados procurou identificar artigos acadêmicos que se relacionassem ao tema implementação de consórcio intermunicipal de forma geral. Para tanto, utilizou-se a Scielo (Scientific Eletronic Library Online) como base de dados para o levantamento, devido, principalmente, a abrangência dos estudos e relevância no cenário nacional.

Na etapa da coleta de dados, adotou-se a palavra-chave "consórcio intermunicipal", obtendo-se 8 artigos, todos referentes aos anos de 2014 a 2018. Cada artigo foi lido e analisado de forma que foram selecionados 3 por serem os únicos que apresentavam casos concretos de implementação de consórcios públicos. Foram selecionados os trabalhos de Henrichs e Meza (2017); Piterman, Rezende e Heller (2016) e Morais e Chaves (2016).

O caráter quantitativo dos indicadores não permite a realização de uma análise mais profunda em relação ao conteúdo dos dados (HAYASHI, 2013), por isso, na etapa da análise dos dados, optou-se pela realização da análise de conteúdo que segundo Bardin (2004), contribui para a descoberta de diferentes significados nos discursos a partir de critérios de frequência. Para tanto, as análises serão dispostas no capítulo seguinte a partir das seguintes categorias de análise: atores; potencialidades e barreiras encontradas ao longo do processo de implementação dos consórcios evidenciados nestes estudos.

\section{ANÁLISE E DISCUSSÃO DOS RESULTADOS}

Para que as análises sejam mais bem exploradas, as mesmas foram divididas em três categorias temáticas: atores; potencialidades e barreiras enfrentadas pelos participantes ao longo do processo de implementação dos consórcios públicos intermunicipais.

É preciso dizer que os consórcios públicos ganharam maior importância com movimento de descentralizado do Estado, sendo este um ponto basilar da reforma da Administração Pública iniciada com maior força a partir da década de 1990 e que, de acordo com Bento (2003), tinha como objetivo a retomada da eficiência das ações governamentais no que diz respeito ao atendimento das necessidades dos cidadãos.

A pesquisa realizada por Morais e Chaves (2016) analisou o consórcio intermunicipal de saúde Cerrado Tocantins Araguaia, cujo objetivo para sua criação foi a busca pela melhoria dos níveis e qualidade dos serviços prestados via Sistema Único de Saúde. O trabalho de Piterman, Rezende e Heller (2016) teve como objetivo analisar a formação e implantação de um consórcio de saneamento básico no sul do Brasil como forma de estímulo para a implantação e gestão das políticas públicas de saneamento. Por fim, Henrichs e Meza (2017) analisaram em sua pesquisa o 
CIF- Consórcio Intermunicipal da Fronteira, que buscou a promoção do desenvolvimento regional devido a escassez de recursos para projetos, obras e melhoria dos serviços públicos.

A primeira categoria de análise refere-se aos atores políticos que são integrantes dos consórcios ora analisados. No trabalho de Henrichs e Meza (2017) tem-se a integração de quatro municípios, sendo um deles argentino, todos de pequeno porte cuja economia gira em torno da agricultura familiar, pouco desenvolvidos devido ao baixo potencial atrativo para atividades industriais. É um grupo com ideologias político partidárias opostas, carente de recebimento de recursos governamentais para fomento do desenvolvimento local. Estes municípios se uniram inicialmente para buscar integração na prestação de serviços de saúde e, posteriormente, atuaram de forma cooperada na promoção da educação e da agricultura.

No estudo de Piterman, Rezende e Heller (2016), os atores envolvidos são municípios que buscaram estabelecer uma colaboração estratégica no sentido de desenvolver habilidades de autogestão de recursos para solucionar problemas relacionados ao saneamento básico. Já os atores envolvidos no consórcio estudado por Morais e Chaves (2016) são municípios com limitações de recursos humanos, tecnologia e estrutura física, que geram impactos negativos na prestação de serviços de saúde.

A partir deste panorama destaca-se que os consórcios podem ser formados entre entes federados de mesma hierarquia ou não. Nos casos estudados as cooperações ocorrem entre municípios. O que se observa é que todos os atores municipais têm procurado este tipo de integração por ser esta uma alternativa para melhorar a prestação dos serviços públicos, compreendidos pela perspectiva de Freitas Júnior e Mesquita (2010) como de alta complexidade e que, por isso, demandam ações coletivas, principalmente devido à insuficiência de recurso individual de cada município que acaba por limitar as ações.

Nenhum dos trabalhos deixou claro se houve algum tipo de capacitação específica para os atores na formação dos consórcios, cuja importância foi anotada por Correia Filho, Baggio e Mello (2017) como forma de ampliar a margem de sucesso na integração e formação destes tipos de parcerias intergovernamentais.

A segunda categoria de análise envolve a identificação das potencialidades que a formação dos consórcios traz para os municípios participantes.

O trabalho de Henrichs e Meza (2017) apontou para a melhoria das relações intergovernamentais, a realização de ações concretas que impulsionaram o desenvolvimento da região, que não seria possível se cada município estivesse atuando sozinho. O fomento da gestão compartilhada das políticas públicas, o que pode contribuir para que as demandas e recursos sejam melhor providos.

A pesquisa de Piterman, Rezende e Heller (2016) revelou como potencialidades o aumento dos recursos socioeconômicos, tecnológicos e humanos, melhor racionalização e transparência na aplicação dos recursos, segurança jurídica e empoderamento político dos consorciados e maior 
potencial para desenvolver políticas públicas. O estudo de Morais e Chaves (2016) apontou como potencialidade a maior autonomia para construção de parcerias e planejamento para além dos limites de cada município.

As potencialidades apresentadas nas pesquisas vão de encontro ao que foi dito por Andrade et al. (2013) e Rocha e Faria (2004) a respeito da cooperação via consórcios intermunicipais e sua capacidade para integrar os municípios por meio da resolução de interesses comuns, do compartilhamento de informações e experiências, possibilidade de aumento de receita e redução de custos, melhor relação entre os atores que compõem a rede interorganizacional. E, de acordo com Borges (2006), este tipo de cooperação é relevante para que os municípios carentes de recursos atuem na promoção não só do interesse local como também de toda região abarcada pelo consórcio.

Por fim, cabe a análise da terceira categoria proposta que trata justamente da identificação de barreiras que podem prejudicar a implementação das ações propostas no âmbito dos consórcios intermunicipais.

A pesquisa de Piterman, Rezende e Heller (2016) não relatou nenhum tipo de barreira encontrada na criação do consórcio estudado. Já Henrichs e Meza (2017) apontaram que a maior barreira foi a ausência de marco legal de formalização da participação do município argentino no consórcio, porque representa um fato que limita as ações e dificulta a unificação dos orçamentos destinados aos objetivos do consórcio. A pesquisa apresentou, também, impasses político- partidários que prejudicaram a execução das ações devido a vaidade política e interesses individuais.

Pela análise de Morais e Chaves (2016), as barreiras encontradas diziam sobre a falta de simetria entre os discursos dos atores participantes do consórcio e os efeitos da implementação das políticas de saúde, falta de clareza dos atores quanto a sua atuação ativa no consórcio, falta de subsídios para ações intersetoriais para resolução de problemas que impactam direta e indiretamente na saúde da população.

As barreiras mencionadas nos estudos analisados como a falta de clareza sobre a distribuição das responsabilidades e ausência de mecanismos formais de regulamentação foram apontadas por Rocha e Faria (2004), que também ressaltaram que a falta de simetria entre os agentes prejudica o fortalecimento dos municípios mais frágeis. A pesquisa de Morais e Chaves (2016) apontou para a falta de simetria entre os planos apresentados e ações implementadas que se entende como igualmente prejudiciais ao fortalecimento do consórcio.

O quadro a seguir traz uma síntese das potencialidades e barreiras encontradas pelos atores ao longo dos processos de implementação dos consórcios intermunicipais.

Figura 2 - Barreiras e potencialidades enfrentadas pelos consórcios públicos 


\begin{tabular}{|c|l|}
\hline \multicolumn{1}{|c|}{ Potencialidades } & \multicolumn{1}{|c|}{ Barreiras } \\
\hline$-\quad$ melhoria na prestação dos serviços & - ausência de marco legal para formalização do con- \\
- utilização de recursos de maneira & sórcio \\
conjunta & - falta de alinhamento com relação às funções de \\
- gestão compartilhada das ações & cada ator na implementação do consórcio \\
- $\quad$ efetivação de parcerias & - divergências políticas e econômicas \\
- promoção do desenvolvimento local & \\
\hline Fonte: Dados da pesquisa.
\end{tabular}

Desta forma, torna-se evidente que a utilização dos consórcios públicos, dentro do contexto da administração pública brasileira, se mostra como uma alternativa capaz de contribuir para promoção do desenvolvimento local e melhoria da prestação dos serviços públicos.

\section{CONSIDERAÇÕES FINAIS}

Dentro da estrutura federalista do Brasil, os municípios possuem função essencial na promoção do bem-comum. Porém, com a promulgação da Constituição Federal de 1988 e alteração do modelo de gestão estatal, os municípios passaram a ter maiores encargos, especialmente no que diz respeito à promoção dos direitos sociais, mas na maioria das vezes os recursos não são suficientes para dar efetividade plena ao atendimento das demandas.

Nesta perspectiva, os consórcios públicos se mostram como uma opção viável para que os municípios possam agir de forma cooperada na resolução de problemas que lhes são comuns, favorecendo a complementação de recursos e a troca de experiências entre os participantes. Por isso, o objetivo desse trabalho foi apresentar as principais barreiras e potencialidades encontradas ao longo do processo de implementação destes consórcios, visando contribuir para a discussão sobre o tema, apontando fatores que devem ser incentivados e outros que precisam ser melhor trabalhados pelos consorciados.

As pesquisas analisadas versaram sobre estruturas consorciais instituídas no modelo horizontal cuja atuação se dá entre entes da mesma esfera governamental, neste caso, os municípios.

Como potencialidades destacou-se que a integração via cooperação se mostrou como um instrumento de auxílio para a resolução de problemas comuns e meio de fomento do desenvolvimento local. A gestão compartilhada se mostrou positiva no que tange à utilização dos recursos humanos, financeiros e tecnológicos, como também para dar mais transparência na execução das ações.

Outro fator positivo é que os consórcios dão maior visibilidade e fortalecimento tanto para os municípios quanto para a região, o que pode ensejar a possibilidade de atração de mais investimentos por parte do governo e demais atores privados.

Já como barreiras a pesquisa evidenciou a dificuldade de entendimento a respeito a função de cada participante do consórcio, a falta de formalização legal e as mazelas político- 
partidárias como pontos frágeis que merecem atenção dos atores que buscam o sucesso desse tipo de cooperação.

Para tanto, acredita-se que o diálogo claro entre as partes e a capacitação dos envolvidos pode contribuir para a redução da interferência política desprovida de fundamento, para que os municípios tenham como resultado a boa qualidade dos serviços públicos e a melhoria da qualidade de vida de sua população através do desenvolvimento da região como um todo.

Esse trabalho possui limitações como, por exemplo, por ter se restringido a analisar apenas a ótica da implementação dos consórcios, porém, espera-se que o mesmo contribua para o fomento de novos estudos com foco na análise de casos práticos de implementação de consórcios públicos como também analisar os resultados nas perspectivas dos agentes públicos e da população, para auxiliar no fortalecimento deste instrumento que muito tem a contribuir para o desenvolvimento de melhores condições de vida para a coletividade.

\section{REFERÊNCIAS}

ABRUCIO, Fernando Luiz. Para além da descentralização: os desafios da coordenação federativa no Brasil. In: FLEURY, SONIA (org.). Democracia, descentralização e desenvolvimento: Brasil \& Espanha. Rio de Janeiro: FGV, 2006. p. 77-125.

ABRUCIO, Fernando Luiz; FILIPPIM, Eliane Salete; DIEGUEZ, Rodrigo Chaloub. Inovação na cooperação intermunicipal no Brasil: a experiência da Federação Catarinense de Municípios (Fecam) na construção de consór- cios públicos. Revista de Administração Pública, Rio de Janeiro, v. 46, n.3, nov./dez. 2013. Disponível em: http://bibliotecadigital.fgv.br/ojs/index.php/ rap/article/view/13987/12873. Acesso em: 15 mar. 2019.

ABRUCIO, Fernando Luiz; SANO, Hironobu; SYDOW, Cristina Toth. Radiografia do associativismo territorial brasileiro: tendências, desafios e impactos sobre as regiões metropolitanas. In: KLINK, Jeroen (org.). Governança das metrópoles. São Paulo: Annablume, 2011. p. 21-48.

ALENCAR, Edgar. Introdução à metodologia de pesquisa. Lavras: UFLA, 2000.

ALEXANDRINO, Marcelo; PAULO, Vicente. Direito administrativo descomplicado. 25. ed. Rio de Janeiro: Forense; São Paulo: Método, 2017.

ANDRADE, Diego César Terra de; OLIVEIRA, Dênis de; PASSADOR, João Luiz; BRITO, Mozar José de. Clubes de futebol x televisão: como Bourdieu pode contribuir para a virada deste jogo de poder. Revista Economia e Gestão, Belo Horizonte, v. 13, n. 32, maio/ago. 2013. Disponível em: http://periodicos.pucminas.br/index.php/economiaegestao/article/view/P.19846606.2013v13n32p130/5677 Acessado em: 15 mar, 2019.

ARAÚJO, Ronaldo Ferreira; ALVARENGA, Lidia. A bibliometria na pesquisa científica da pós-graduação brasi- leira de 1987 a 2007. Encontros Bibli, Florianópolis, v. 16, n. 31, p. 51-70, 2011. Disponível em: https://periodicos.ufsc.br/index.php/eb/article/view/1518- 
2924.2011v16n31p51. Acesso em: 15 mar. 2019.

BARDIN, Laurence. Análise de conteúdo. Lisboa: Edições 70, 2004.

BENTO, Leonardo Valles. Governança e governabilidade na reforma do Estado: entre eficiência e democratização. Barueri: Manole, 2003.

BORBA, Érika Loureiro; PEREIRA, José Roberto; TORRES, Kelly Aparecida. O interesse público na perspectiva de Hobbes, Locke, Rousseau e Tocqueville. In: CONGRESSO DE ADMINISTRAÇÃO, SOCIEDADE E INOVAÇÃO, 2012, Volta Redonda. Anais [...]. Volta Redonda, 2012. Disponível em: https://www.academia.edu/2361978/O_interesse_público_na_ perspectiva_de_Hobbes_Locke_Rousseau_e_Tocqueville. Acesso em: 20 mar. 2019.

BORGES, Alice Gonzalez. Consórcios públicos e Estatuto da Cidade. Revista Jus Navigandi, Teresina, ano 11, n. 1128, ago. 2006. Disponível em: https://jus.com.br/artigos/8693. Acesso em: 15 jul. 2019.

BRASIL. [Constituição (1988)]. Constituição da República Federativa do Brasil de 1988. Brasília: Presidência da Republica, 1988. Disponível em: http://www.planalto.gov.br/ccivil_03/ constituicao/constituicao.htm. Acesso em: 12 ja/01/2019.

BRASIL. Lei no 11.107, de 6 de abril de 2005. Dispõe sobre normas gerais de contratação de consórcios públicos e dá outras providências. Brasília, DF: Presiência da República, 2005. Disponível em: http://www.planalto.gov.br/ccivil_03/_Ato2004-2006/2005/Lei/L11107.htm. Acesso em: 15 jul. 2019.

BRESSER-PEREIRA, Luiz Carlos. Construindo o Estado Republicano: democracia e reforma da gestão pública. Rio de Janeiro: FGV, 2009.

CABRAL NETO, Antônio. Descentralização administrativa. In: OLIVEIRA, Dalila Andrade; DUARTE, Adriana Cancella; VIEIRA, Lívia Fraga. Dicionário: trabalho, profissão e condição docente. Belo Horizonte: UFMG; Faculdade de Educação, 2010. CD Rom.

CALDERAN, Thanabi Bellenzier; MAZZARINO, Jane Márcia; TURATI, Luciana. A potencialidade dos consórcios intermunicipais frente à política nacional de resíduos sólidos: estudo de caso no Corede - Vale do Taquari, RS, Brasil. Revista Estudo e Debate, v. 24, n. 3, 2017. Disponível em: http://www.univates.br/revistas/index.php/estudoedebate/article/view/1323 Acesso em: 19 mar. 2019.

CARVALHO, Matheus. Manual de direito administrativo. 4. ed. Salvador: JusPODIVM, 2017.

COHN, Amélia. Os governos municipais e as políticas sociais. In: SOARES, Jose Arlindo; CACCIA-BAVA. Silvio (org.). Os desafios da gestão municipal democrática. São Paulo: Cortez, 2002.

CORREIA FILHO, Wlademir Leite; BAGGIO, Daniel Knebel; MELO, Alcielne de Souza. Consórcio intermunicipal: cooperação como fonte de desenvolvimento regional. In: SEMINÁRIO INTERNACIONAL SOBRE DESENVOLVIMENTO REGIONAL, 8., 2017, Santa Cruz do Sul, RS. Anais [...]. santa Cruz do Sul, 2017. Disponível em: http://online.unisc. br/acadnet/anais/index.php/sidr/article/view/16208/4292. Acesso em: 21 mar. 2019. 
DI PIETRO, Maria Sylvia Zanella. Direito administrativo. 31. ed. Rio de Janeiro: Forense, 2018.

FARIAS, Talden. Consórcios públicos, federalismo cooperativo e intermunicipalidade. A\&C -

Revista de Direito Administrativo e Constitucional, Belo Horizonte, ano 17, n. 70, p. 237-255, out./dez. 2017. Disponível em: http://www.revistaaec.com/index.php/revistaaec/article/view/499. Acesso em: 9 out. 2019.

FREITAS JÚNIOR, Dionysio Borges de; MESQUITA, Daniel Leite. Consórcios Intermunicipais de Políticas Públicas em Minas Gerais: redes para a prestação eficiente de serviços ao cidadão. In: ENCONTRO DA ANPAD, 34., 2010, Rio de Janiero. Anais [...]. Rio de Janeiro, 2010. Disponível em: http://www.anpad.org.br/admin/pdf/apb1375.pdf. Acesso em: 21 mar. 2019.

FREITAS, Leana Oliveira. Políticas públicas, descentralização e participação popular. Revista Katálysis, Florianópolis, v. 18, n. 1, p. 113-122, jun. 2015. Disponível em: http://www.scielo.br/ scielo.php?script=sci_arttext\&pid=S1414- 49802015000100113\&lng=en\&nrm=iso. Acesso em: 29 abr. 2019.

HAYASHI, Carlos Roberto Massao. Apontamentos sobre a coleta de dados em estudos bibliométricos e cientométricos. Revista Filosofia e Educação, São Paulo, v. 5, n. 2, out. 2013.

HENRICHS, Joanni Aparecida; MEZA, Maria Lúcia Figueiredo Gomes de. Governança multinível para o desenvolvimento regional: um estudo de caso do Consórcio Intermunicipal da Fronteira. Revista Brasileira de Gestão Urbana, Curitiba, v. 9, n. 1, p. 124-138, abr. 2017. Doi: 10.1590/2175-3369.009.001.ao03.

LIMA, Tatiana Maria Silva Mello de. O Federalismo Brasileiro: uma forma de estado peculiar. 2008.

LINHARES, Paulo de Tarso Frazão Soares; MESSENBERG, Roberto Pires; FERREIRA, Ana Paula Lima. Transformações na Federação Brasileira: o consórcio intermunicipal no Brasil do início do século XXI. Boletim de Análise Político-Institucional, Brasília, n. 12, jul./dez. 2017. Disponível em: http://repositorio.ipea.gov.br/handle/11058/8102. Acesso em: 15 mar. 2019.

MATOS, Fernanda; DIAS, Reinaldo. A gestão de resíduos sólidos e a formação de consórcios intermunicipais. Revista em Agronegócio e Meio Ambiente, Maringá, v. 4, n. 3, 2011. Disponível em: https://periodicos.unicesumar.edu.br/index.php/rama/article/view/1935/1299. Acesso em: 19 mar. 2019.

MEDAUAR, Odete. Direito administrativo moderno. 21. ed. Belo Horizonte: Fórum, 2018.

MEIRELLES, Hely Lopes. Direito municipal brasileiro. 16. ed. São Paulo: Malheiros, 2008.

MINAYO, Maria Cecília de Souza. Pesquisa social: teoria, método e criatividade. Petrópolis: Vozes, 1995.

MONTEIRO, Lilian Alfaia. Descentralização administrativo e participação popular em políticas culturais: o caso de um ponto de cultura em Niterói. In: ENCONTRO DA ANPAD, 35., 2011,. Rio de Janeiro. Anais [...]. Rio de janeiro, 2011. Disponível em: http://www.anpad.org.br/admin/ pdf/APB1305.pdf Acessado em: 19 mar. 2019. 
MORAIS, Vânia Soares de; CHAVES, André Preissler Loureiro. Percepção dos gestores municipais de saúde relacionada à saúde ambiental: consórcio intermunicipal de saúde Cerrado Tocantins Araguaia. Saúde e Sociedade, São Paulo, v. 25, n. 2, p. 349-360, jun. 2016. Disponível em: http://www.scielo.br/scielo.php?script=sci_arttext\&pid=S010412902016000200349\&lng=en\&nrm=iso. Acesso em: 8 abr. 2019.

OLIVEIRA, Rafael Carvalho Rezende. Curso de direito administrativo. 5. ed. São Paulo: Método, 2017.

OLIVEIRA, Vitor França Dias. Introdução ao federalismo fiscal brasileiro. Revista Âmbito Jurídico,São Paulo, mar. 2013. Disponível em: http://www.ambito-juridico.com.br/site/?n_ link=revista_artigos_leitura\&artigo_id=12642. Acesso em: 10 nov. 2018.

PITERMAN, Ana; REZENDE, Sonaly Cristina; HELLER, Léo. Capital social como conceitochave para a avaliação do sucesso de consórcios intermunicipais: o caso do CISMAE, Paraná. Engenharia Sanitaria e Ambiental, Rio de Janeiro, v. 21, n. 4, p. 825-834, dez. 2016. Disponível em: http://www.scielo.br/scielo.php?script=sci_abstract\&pid=S1413$41522016000400825 \& \operatorname{lng}=$ pt\&nrm=iso. Acesso em: 10 mar. 2019.

REZENDE, João Batista. Administração pública em municípios de pequeno porte do sul de Minas Gerais: velhas questões, modernas leis e práticas patrimonialistas. 2011. Tese (Doutorado em Administração) - Universidade Federal de Lavras, Lavras, 2011. Disponível em: http://www. repositorio.fjp.mg.gov.br/handle/123456789/150. Acesso em: 25 mar. 2019.

RIBEIRO, Márcia Carla Pereira; RAZUK, Nahima Peron Coelho. Consórcio público e gerenciamento de resíduos sólidos: aspectos de eficiência e cooperação. Revista Pensar, Fortaleza, v. 19, n. 1, p. 151-178, jan./abr. 2014. Disponível em: https://periodicos.unifor.br/rpen/ article/viewFile/3090/pdf. Acesso em: 9 out. 2019.

ROCHA, Carlos Vasconcelos; FARIA, Carlos Aurélio Pimenta de. Cooperação intermunicipal, reterritorialização da gestão pública e provisão de bens e serviços sociais no Brasil contemporâneo: a experiência dos Consór- cios de Saúde de Minas Gerais. Revista Cadernos Metrópole, São Paulo, n. 11, 2004. Disponível em: https://revistas.pucsp.br/index.php/ metropole/article/view/8815. Acesso em: 17 mar. 2019.

RODRIGUES, Fillipe Azevedo. Análise econômica dos consórcios públicos municipais: teoria dos jogos como instrumento maximizador da eficiência administrativa. Revista Jurídica da Presidência, Brasília, v. 15, n. 17, out. 2013/jan. 2014. Disponível em: http://dspace/xmlui/ bitstream/item/14933/e_home_ndj_dados_biblioteca_BDM_BDM89814.pdf?sequence=1 Acessado em: 9 out. 2019 .

SARAVIA, Enrique. Introdução à teoria da política pública. In: SARAVIA, Enrique; FERRAREZI, Elisabete (org.). Políticas públicas. Brasília: ENAP, 2006. v. 1, p. 21-42.

TRIVIÑOS, Augusto Nibaldo Silva. Introdução à pesquisa em ciências sociais: a pesquisa qualitativa em educação. São Paulo: Atlas, 1992.

VIANA, Ana Luiza D’Ávila; LIMA, Luciana Dias de; OLIVEIRA, Roberta Gondim de. Descentralização e federalismo: a política de saúde em novo contexto - lições do caso brasileiro. Ciência \& Saúde Coletiva, São Paulo, v. 7, n. 3, p. 493-507, 2002. Disponível em: http://www. 
scielo.br/pdf/csc/v7n3/13027.pdf. Acesso em: 23 mar. 2019.

Como citar: BORBA, Érika Loureiro; OLIVEIRA, Dênis Renato de. Os consórcios intermunicipais: entre barreiras e potencialidades. Revista do Direito Público, Londrina, v. 15, n. 2, p. 135-154, ago. 2020. DOI: 10.5433/24157-108104-1.2020v15n2p.135. ISSN: 1980-511X

Recebido em: 15/05/2019

Aprovado em: 14/10/2019 